The paper studies power losses in transformers due to non-linear loads. The research aims to analyze the power loss in a single-phase dry transformer under a non-linear load. The research uses an $S W 43 W$ Power supply type, FlukeView Power Ouality Analyzer as a DC or AC power supply on the primary side of the transformer. The non-linear load is connected to the secondary side. The loading test of the dry transformer was carried out at non-linear loads. The load variations used $0 \% ; 12.5 \% ; 25 \% ; 37.5 \% ; 50 \% ; 62.5 \%$; $75 \% ; 87.5 \%$ and $100 \%$, as well as variations in the THD value by adjusting the ignition angle $(\alpha)$. The non-linear loads used are Half-Wave Rectifier and Controlled Half-Wave Rectifier with resistive loads with variations in THD values. The results showed that the transformer losses comprised Pno load and Pload. The operation of the transformer with constant input voltage and frequency with $T H D v<5 \%$ resulted in a constant Pno load value at all load values. The greater the percentage of the load, the higher the load. The increase in THD because of non-linear load will increase the load on the transformer. The value of the derating factor is obtained by connecting the increase in losses ( $\triangle$ PLosses), which is influenced by THD and the increase in temperature $\mathrm{T}\left({ }^{\circ} \mathrm{C}\right)$ in dry transformers. When the transformer is loaded with a non-linear load, the derating factor $<1$. THD and derating factor form a linear relationship, when THD increases, the derating factor value decreases. Linear load on the transformer causes a decrease in its capacity, but if it gets a non-linear load with $T H D=39.1 \%$, it can withstand $a$ load of $84.294 \%$, besides the increase in total harmonic distortion will increase losses and reduce transformer capacity

Keywords: Dry Transformer, Single-Phase, NonLinear Load, Loss, Derating factor, Total Harmonic Distortion

\section{ANALYSIS OF LOSS ON SINGLE-PHASE DRY TRANSFORMERS WITH NON-LINEAR LOAD}

\author{
Harrij Mukti Khristiana \\ Correspondingauthor \\ Doctoral Student* \\ Department of Electrical Engineering \\ State Polytechnic of Malang \\ JI. Soekarno-Hatta No. 9, Malang, \\ Jawa-Timur, Indonesia, 65141 \\ E-mail: harrijmukti007@gmail.com \\ Sudjito Soeparman \\ PhD, Professor* \\ S I a met Wahyudi \\ Doctor of Mechanical Engineering, \\ Associate Professor* \\ Rini Nur Hasanah \\ Department of Electrical Engineering** \\ *Department of Mechanical Engineering** \\ **Brawijaya University
}

Doctor of Electrical Engineering, Associate Professor

Jl. Mayjend Haryono, 167, Malang, Indonesia, 65145
Received date 09.08.2021

Accepted date 14.10.2021

Published date 29.10.2021
How to Cite: Khristiana, H. M., Soeparman, S., Wahyudi, S., Hasanah, R. N. (2021). Analysis of loss on single-phase dry transformers with non-linear load. Eastern-European Journal of Enterprise Technologies, 5 (8 (113)), 17-22 doi: https://doi.org/10.15587/1729-4061.2021.240233

\section{Introduction}

Transformers have a critical role in electrical power systems. Therefore, an excellent performance must be guaranteed. Efficiency is one among several factors that can judge the performance of a transformer. It is directly related to thermal stressing on the transformer. Although electronic equipment has many benefits, the use of electronic loads, which are mostly non-linear types of loads, causes harmonics. Harmonic is a phenomenon that arises due to the use of non-linear loads, namely loads whose current component is not proportional to the voltage component so that the current wave is not the same as the voltage wave (distorted). The existence of these harmonics causes the current and voltage waves to become defective and no longer sinusoidal because of the interaction between the system's sine wave (fundamental wave) and other waves that have a frequency multiple of integers from the fundamental frequency.

Harmonics are an important thing to pay attention to in transformers because transformers are generally designed to operate at a certain frequency rating with a linear load, whereas the load on the transformer is a non-linear type of load [1].

In transformers, the consequence of the emergence of these harmonics is an increase in losses, especially in the coils [2]. The increase in losses is also followed by other problems such as increased temperature, insulation damage and reduced transformer life [3].

The use of non-linear loads has a significant impact on the transformer temperature, caused by the flow of current, which will increase the heat. Under linear load conditions, the current generated is only the fundamental component. But in non-linear conditions, the current consists of fundamental and harmonic components. As a result, the current will be higher and increase the temperature in the transformer and affect the efficiency, capacity and performance of the transformer [4]. Dry-type transformers are one of the main types of transformers besides oil-filled transformers and gas-insulated transformers [5].

Therefore, researchers are interested in analyzing the power loss on a single-phase dry transformer under a non-linear load. The analysis carried out includes losses and derating caused by dry transformers due to the influence of non-linear loads.

\section{Literature review and problem statement}

Research on transformer performance related to loading type has been the focus of attention during the last few years 
The effect of changes in the loading frequency on losses, especially on eddy current losses in a single-phase $25 \mathrm{kVA}$ transformer was examined. In addition, the influence of non-linear load on derating and Reduction in Apparent Power Rating (RAPR) was studied. Derating was determined by the K-Factor. Using non-linear loads can increase eddy current losses up to 6x compared to the use of linear loads, and the efficiency of the transformer under a non-linear load is lower than under a linear load. The results showed that the increase in eddy current losses due to harmonic loads can reduce the maximum load current on the transformer. [6] stated that the efficiency of the transformer under a non-linear load is lower than when it is loaded with a linear load. Under a non-linear load, the transformer cannot be operated at kVA full load, therefore derating is required. Derating is determined by the Taheri K-Factor method. [7] discussed the modeling and simulation of loading capability and hot-spot temperature on oil transformers during harmonic conditions. The model used is the dynamic thermal model and the IEEE Guide. Therefore, in the study, we will discuss the effect of non-linear load on power loss and derating in a single-phase dry transformer.

Standard transformers for delivering electricity provided by the state to household consumers are generally not designed to use non-linear loads containing harmonic currents (IEEE Std. 519-2014) [8]. Therefore, the load harmonic currents hazard level of the impacting the transformer (K-factor) higher indicates overheating and insulation failure. Other losses in the coil cause insulation damage and an increase in temperature in the transformer, which results in a decrease in efficiency, performance, and capacity (it is necessary to reduce the maximum load or derating to prevent the overheat) [9]. [10] found that harmonic pollution increases losses, so it is necessary to improve power quality by reducing non-linear loads. As a comparison, THD for linear loads does not experience distortion $(\mathrm{THD}=4.0 \%)$, while for non-linear loads experiences substantial distortion (THD $=26 \%$ for inductive loads and THD $75 \%$ for capacitive loads). However, the previous studies limit their focus to high THD values while they do not further discuss THD's increase.

[11] discussed the effect of changes in the loading frequency on losses, especially on eddy current losses in a single-phase $25 \mathrm{kVA}$ transformer. The emergence of harmonics due to non-linear loads affects the derating and Reduction in Apparent Power Rating (RAPR). [12] found that the type of load applied to the transformer rating affects loss and efficiency. The use of non-linear loads can increase eddy current losses up to 6x compared to the use of linear loads. The efficiency of the transformer under a non-linear load is lower than when it is linearly loaded, and the determination of derating is also done by the K-Factor.

[4] conducted a study on the proximity effect on transformers caused by harmonic loads. The proximity effect affects the increase in the $\mathrm{AC}$ resistance of the conductor compared to the DC resistance. The results show that the increase in eddy current losses due to harmonic loads can reduce the maximum load current on the transformer.

[13] conducted a study on a 3-phase distribution transformer under balanced loading conditions. The results show that the efficiency of the transformer when it is non-linearly loaded is lower than when it is under a linear load. When the load is non-linear, the transformer cannot be operated at kVA full load, because it requires a rating.
[9] discussed the determination of transformer ratings due to loading with different methods. The increase in Total Harmonic Distortion (THD) affects the temperature increase, where the value of the multiplier constant for THD is obtained to obtain the percentage increase in the required transformer rating. [7] conducted a study by changing the percentage load of 3-phase dry transformers with a short-circuit test to determine the temperature distribution. The coil temperature measurement is carried out using a thermocouple, but it does not indicate the specific position of the thermocouple placement on the coil. Numerical models were compiled using the FLUENT 6.3 application software. The results showed that the addition of the load will increase the temperature of the coil.

[14] discussed the modeling and simulation of loading capability and hot-spot temperature on oil transformers during harmonic conditions. The model used is the dynamic thermal model and the IEEE Guide. The simulation results show that the increase in harmonic currents causes an increase in the temperature of the hot-spot and top oil.

Therefore, in this study, we will discuss the effect of the type of load on the energy balance of dry transformers with the type of concentric coil and on the consumption of electrical energy, both for service providers and consumers of electrical energy. The amount of losses and temperature in the coil will be related to the energy balance in the transformer. The amount of losses and temperature in the coil are then used as the basis for estimating the decrease in the derating capacity of the transformer due to harmonics.

\section{The aim and objectives of the study}

The aim of the study is to examine the power loss in a single-phase dry transformer under a non-linear load.

To achieve this aim, the following objectives are accomplished:

- to conduct a study of the use of non-linear loads on dry transformer losses;

- to conduct a study of the use of non-linear loads on derating dry transformers.

\section{Material and Methods}

\section{1. The main hypothesis of the study}

This study will specifically provide an additional review on the impact of increased losses based on the Eddy Current Losses value. This idea arises because there is an increase in active energy (winding stray losses and other losses) and reactive energy (leakage flux energy and stray magnetic energy). These factors will trigger an increase in dissipated energy, which is indicated by an increase in temperature at the distribution transformer and mains, where the hazard level will increase and harm energy producers and consumers. The use of a non-linear load on the transformer will increase the current in the coil, which results in increased losses in the transformer compared to when the transformer operates with a linear load.

Single-phase dry-type transformer is used as the main object in this research. Single-phase transformers are used because they are the simplest building blocks to form threephase or other types of transformers. First, the basic parameter test is carried out to obtain the transformer equivalent 
circuit. The transformer is then loaded with a non-linear load. Specifications: dry transformer is Single-Phase Dry Transformer; Coil Type is Concentric; Core Diameter is $80 \mathrm{~mm}$; Nominal Power/Frequency is $480 \mathrm{VA} / 50 \mathrm{~Hz}$; High Voltage side voltage is $220 \mathrm{~V}$; Low Voltage side voltage is $48 \mathrm{~V}$; High Voltage side current is 2,182 A; Low Voltage side current is $10 \mathrm{~A}$ and Coil Material is copper.

\section{2. Experimental Set-up}

The research design was developed as shown in Fig. 1.

\section{Results of Research on Non-Linear Loads on Transformers}

\author{
5. 1. Effect of Non-Linear Load on Losses in Dry \\ Transformer \\ The losses in the transformer consist of [15]: \\ - Core Losses. \\ Iron loss of core loss consists of:
}

a) Hysteresis losses, ice losses caused by the alternating flux in the iron core (1),

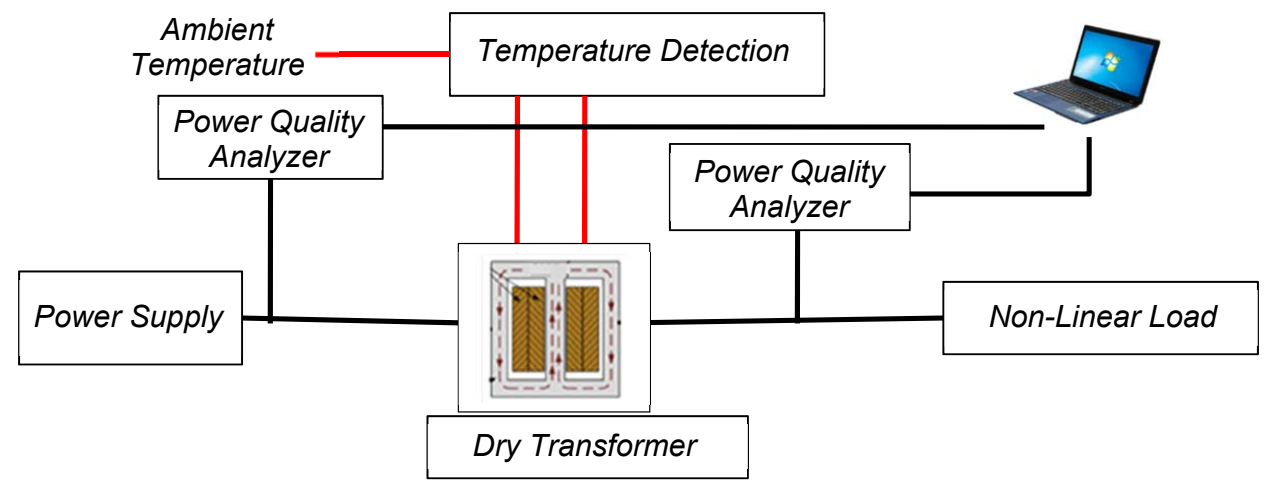

$P_{h}=K_{h} f B_{\max }^{1,6}$ (watts),

where, $P_{h}$ is hysteresis loss $(\mathrm{W}), \mathrm{K}_{\mathrm{h}}$ is hysteresis constant, $\mathrm{f}$ is frequency $(\mathrm{Hz}), B_{\max }$ is maximum flux density (weber $\left./ \mathrm{m}^{2}\right)$;

b) Eddy current losses, namely losses caused by eddy currents in the iron core. The magnitude of the eddy current loss (2),

$$
P_{e}=K_{e} f^{2} B_{\max }^{2} \text { (watts), }
$$

where, $P_{e}$ is eddy current loss (W), $K_{e}$ is eddy current constant, so the total iron loss (core loss) (3),

$$
P_{\text {core }}=P_{h}+P_{e} .
$$

The maximum flux density $\left(B_{\max }\right)$ of the core and the supply frequency affected the hysteresis loss and eddy current loss. When a transformer is connected to a constant frequency supply and a constant voltage, then the values of $f$ and $B_{\max }$ are constant. Thus, the core loss is constant at all load values.

Load losses consist of ohmic loss, eddy current loss and other stray loss (4)-(6)

$$
\begin{aligned}
& P_{L O A D}=P_{D C}+P_{E C}+P_{O S L}, \\
& P_{D C}=I^{2} R_{D C}, \quad P_{D C}=I_{1}^{2} R_{1}+I_{2}^{2} R_{2}, \\
& P_{T S L}=P_{E C}+P_{O S L},
\end{aligned}
$$

$P_{D C}$ represents the loss caused by the load current and the DC resistance in the coil. $P_{T S L}$ states the total stray losses consisting of $P_{E C}$ and $P_{O S L}$. PEC is the eddy current loss in the coil and $\mathrm{P}_{\mathrm{OSL}}$ represents electromagnetic loss in other parts (e. g. at clamp core, tank etc.) or other stray losses.

For the dry transformer (IEEE Std C57-110-1998, 1999) (7),

$$
P_{E C}=0.67 x P_{T S L}
$$

where Total losses,

$$
P_{\text {TOTAL }}=P_{C O R E}+P_{L O A D}
$$

- Copper Loss (Pcu)

The coil resistance (R) and the load current (I) flowing in the copper wire caused the copper loss (9)

Fig. 2. Loaded Transformer Test Circuit 


$$
P_{C u}=I^{2} R
$$

The amount of copper loss varies depending on changes in the transformer's load, which results in changes in the load current. So, the amount of copper loss is also not constant and depends on the magnitude of the load.

The difference in non-linear load affects the dry transformer losses. In this test, the dry transformer load was varied from $0 \%$ to $100 \%$. The variation of the Total Harmonic Distortion (THD) value is done by setting the ignition angle $(\alpha)$. The value of $=0^{\circ}$ is applied to the Half-Wave Rectifier and $0^{\circ}<\alpha<180^{\circ}$ is applied to the Controlled Half-Wave Rectifier. The greater the value of the angle applied, the higher the THD value. The values used in this Controlled HalfWave Rectifier are $0^{\circ}(\mathrm{THDi}=39.1 \%), 36^{\circ}(\mathrm{THDi}=50.4 \%)$, $72^{\circ}(\mathrm{THDi}=66.7 \%), 108^{\circ}(\mathrm{THDi}=80.1 \%)$ and $144^{\circ}(\mathrm{THDi}=$ $=88.9 \%)$.

Fig. 3 shows the total losses on dry transformers by the type of load. The total loss consists of $P_{\text {noload }}$ and $P_{\text {load. }}$ Harmonic effects on transformers are divided into two, namely: harmonics on current will increase copper losses and stray losses, and harmonics on voltage will increase core losses. When a transformer is connected to a constant frequency supply and a constant voltage, then the values of $f$ and $B_{\max }$ are constant. The test is applied to a fixed input voltage and frequency $(220 \mathrm{~V} / 50 \mathrm{~Hz})$ with $\mathrm{THDv}=2.2 \%$, so that it still meets the recommended voltage harmonic standard based on the IEEE standard 519-1992 (THDv<5\%). Therefore, the $\mathrm{P}_{\text {no load value (core }}$ loss) is constant at all load values.

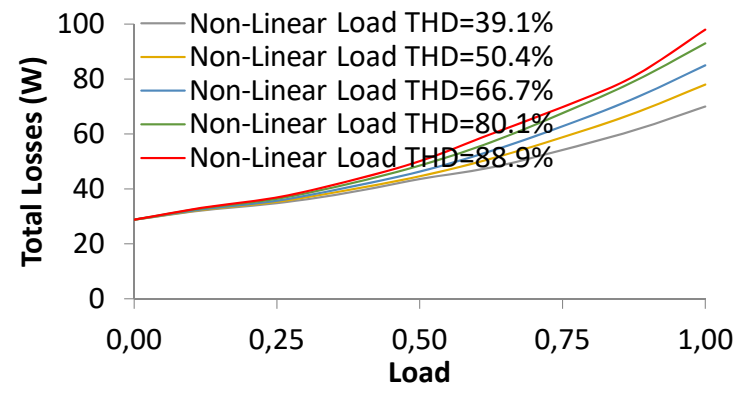

Fig. 3. Total Losses under Non-linear Load on Dry transformer

The effect of loading variations causes changes in $P_{\mathrm{DC}}$ losses. The dry transformer load is varied from $0-100 \%$ with variations in the value of Total Harmonic Distortion (THD). Fig. 4 shows $P_{\mathrm{DC}}$ losses at a non-linear load. $P_{\mathrm{DC}}$ losses are affected by the current and DC resistance of the coil.

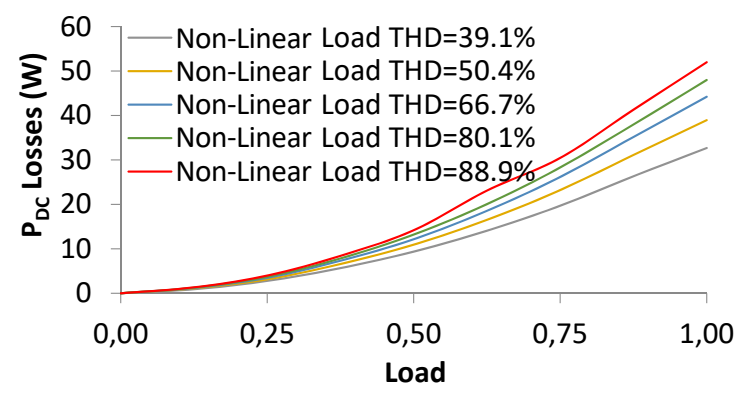

Fig. 4. $P_{D C}$ Losses under Non-linear Load on Dry transformer
Fig. 5 shows $P_{\text {Eddy current losses at a non-linear load and }}$ Fig. 6 shows $P_{\text {other stray losses }}$ at a non-linear load. Stray losses are an important part of heating because of the effect of non-sinusoidal current waves. Stray losses are eddy current losses caused by electromagnetic fields in the coils, clamps, cores and other parts of the transformer. Stray losses consist of winding stray losses $\left(P_{\mathrm{EC}}\right)$ and stray losses in parts other than the coil $\left(P_{\mathrm{OSL}}\right)$.

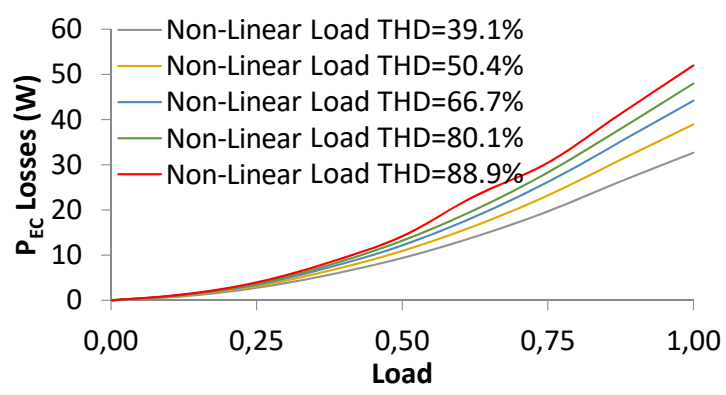

Fig. 5. $P_{\text {Eddy current losses }}$ under Non-linear load on Dry transformer

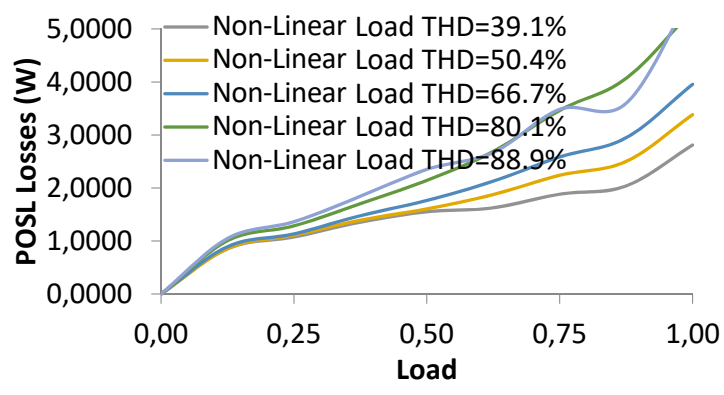

Fig. 6. $P_{\text {other stray losses }}$ under Non-linear load on Dry transformer

At a non-linear load, the full load state with a current THD of $39.1 \%$ got $P_{\mathrm{DC}}$ losses of $32.7 \mathrm{~W}$, winding eddy current losses of $5.71 \mathrm{~W}$ and other stray losses of $2.81 \mathrm{~W}$. So that the dry transformer got an increase in losses of $11.643 \%$, including an increase in losses $3.66 \%, P_{\mathrm{DC}}$ increase in losses winding eddy current loss is $259.34 \%$ and the increase in other stray loss is $259.42 \%$ compared to a linear load. When viewed from the increase in losses because of these harmonics, these harmonics have the greatest impact on the increase in eddy current losses. This is closely related to the occurrence of skin effects and proximity effects, which are influenced by the magnitude of the harmonic frequency so that it affects the $\mathrm{AC}$ resistance of the transformer coil.

\section{2. Effect of Non-Linear Load on Derating Dry Trans-} former

The current harmonics cause heating in the transformer parts so that it will cause increased losses and decreased efficiency in the transformer. With a decrease in the transformer's efficiency, there will be a decrease in the rated power capacity of the transformer.

The relationship between the increase in losses $\left(\Delta P_{\text {Losses }}\right)$ and the increase in temperature $\Delta T\left({ }^{\circ} \mathrm{C}\right)$ is shown in Fig. 7. The temperature at a linear load with $\mathrm{PF}=1$ is used as a reference value $(\mathrm{THD}=0 \%)$. 


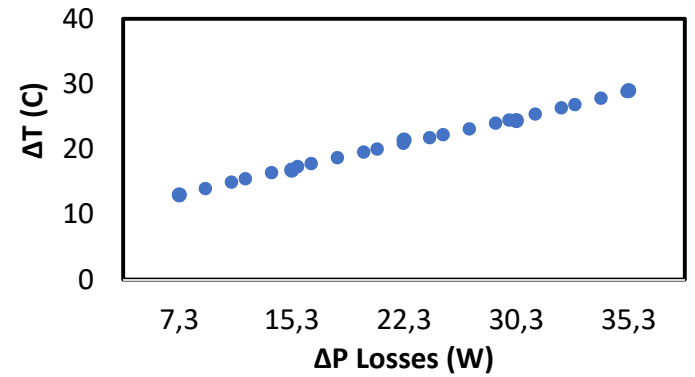

Fig. 7. Relationship between $\Delta P_{\text {Losses }}$ and $\Delta T\left({ }^{\circ} \mathrm{C}\right)$

Fig. 7 shows the relationship between the increase in losses $\left(\Delta P_{\text {Losses }}\right)$ and the increase in temperature $\Delta T\left({ }^{\circ} \mathrm{C}\right)$. It can be seen that $\Delta P_{\text {Losses }}$ has a linear relationship with $\Delta T\left({ }^{\circ} \mathrm{C}\right)$.

The effect of Total Harmonic Distortion (THD) on the Derating Factor is shown in Fig. 8. The higher the THD value, the higher the temperature, so a derating factor is needed to avoid transformer overheating. The THD value with a non-linear load affects the derating factor due to harmonics. The derating factor value is influenced by the increase in losses $\left(\Delta \mathrm{P}_{\text {Losses }}\right)$, and this is related to the increase in temperature $\Delta T\left({ }^{\circ} \mathrm{C}\right)$ caused by harmonics.

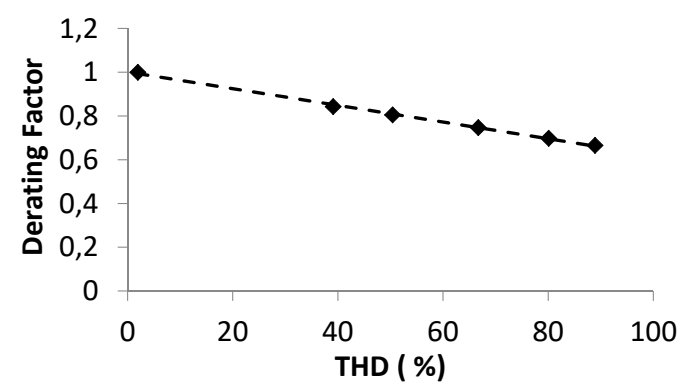

Fig. 8. Relationship between THD and Derating Factor

When the transformer is linearly loaded where there is no harmonic disturbance in the system, the derating factor $=1$ is obtained, so that there is no decrease in the transformer capacity and the transformer can be loaded $100 \%$. However, when the transformer is loaded with a non-linear load, the derating factor $<1$. When the transformer is loaded with a non-linear load with $\mathrm{THD}=39.1 \%$, a derating factor $=0.84294$ is needed. This means that at $1 / \mathrm{THD}=39.1 \%$ the transformer is only allowed to be loaded with $84.294 \%$ to avoid overheating due to harmonics.

\section{Discussion of the experimental results of non-linear loads on transformers}

In the study, a dry-type transformer by using natural air circulation for cooling is used. The ambient temperature is set at $27{ }^{\circ} \mathrm{C}$ and at constant input voltage and frequency $(220 \mathrm{~V} / 50 \mathrm{~Hz})$ with $\mathrm{THDv}=2.2 \%$. In addition, the derating factor as a function of THD is used as an approximation method to determine the transformer loading rating at different THD values.

Fig. 3 shows Load losses ( $\left.P_{\text {load }}\right)$ consist of a) ohmic losses $\left(P_{\mathrm{DC}}\right)$ and b) Eddy current losses in the coils caused by leakage of alternating flux in the coils and stray losses or Eddy currents in clamps, cores and other parts caused by leakage flux. The load test results show that the higher the percentage of load on the transformer, the higher the losses. The value of load varies depending on changes in the transformer's load, which results in changes in the load current. The greater the percentage of the load, the higher the $P_{\text {load }}$. The Total Losses value is higher when the load THD value is increased.

The dry transformer coil conductor uses copper material because it has a low material resistivity $\left(\rho_{20}=1.723 \times 10^{-8}\right)$. The resistivity of the material will affect the coil resis tance $\left(R_{D C}=\frac{\rho_{20} x L}{A}\right)$. The resistivity of the material is affected by temperature. The resistivity of the material generally exists at a temperature of $20^{\circ} \mathrm{C}$, so the DC resistance of the conductor will be affected by temperature $\left(R_{\mathrm{DC}}=\frac{\rho_{20} x L}{A}\left[1+\alpha_{20}(\theta-20)\right]\right)$. Fig. 4 shows the increase in the percentage of the load has an impact on increasing the load current $(I)$. Thus, an increase in temperature will increase the DC resistance and an increase in current due to an increase in load has an increasing impact (PDC). The value of $P_{\mathrm{DC}}$ losses is lower when the percentage of loading is lower and vice versa. The value of $P_{\text {DC }}$ losses increases with increasing THD value.

There are two effects that cause winding eddy current losses $\left(P_{\mathrm{EC}}\right)$, namely the skin effect and the proximity effect. Winding eddy current losses are directly proportional to the square of the current and the square of the frequency $\left(P_{E C} \infty I^{2} \times f^{2}\right)$. Coil conductors are generally designed with a low skin effect factor $\left(y_{s}\right)$ so that the skin effect can be ruled out. Therefore, the impact of low-order harmonics on the skin effect on the transformer can be neglected. The proximity effect is caused by the flow of current in a conductor or a magnetic field that induces eddy currents in other adjacent conductors. The eddy current will dissipate power and contribute to the electrical loss of the coil, which increases the loss caused by ohmic losses $\left(P_{\mathrm{DC}}\right)$. Fig. 5, 6 show $P_{\text {Eddy current losses }}$ and $P_{\text {Other stray losses }}$ values are higher when the loading percentage is higher and vice versa. The value of $P_{\text {Eddy current losses }}$ and $P_{\text {Other stray losses }}$ increases with increasing THD value.

Fig. 8 shows the higher the THD value, the higher the temperature, so a derating factor is needed to avoid transformer overheating. When the transformer is linearly loaded where there is no harmonic disturbance in the system, the derating factor $=1$ is obtained, so that there is no decrease in the transformer's capacity and the transformer can be loaded $100 \%$. However, when the transformer is loaded with a non-linear load, the derating factor $<1$. Based on Fig. 8, it can be seen that there is a linear relationship between THD and the derating factor. It can be seen that when THD increases, the derating factor value decreases.

Derating transformer is an effort to reduce transformer loading capacity caused by harmonic load so that the transformer does not overheat. The derating factor value can be obtained by connecting the increase in losses $\left(\Delta P_{\text {Losses }}\right)$, which is affected by THD and the increase in temperature $T\left({ }^{\circ} \mathrm{C}\right)$ in dry transformers. If a transformer is used to supply loads containing harmonics, the transformer should not be operated under full load and the load should be reduced.

\section{Conclusions}

1. At full linear load, losses are $31.5 \mathrm{~W}$, winding eddy current losses are $1.59 \mathrm{~W}$ and other stray losses are $0.78 \mathrm{~W}$ 
with a current THD value of $1.95 \%$. At a non-linear load, the full load state with a current THD of $39.1 \%$ obtained losses of $32.7 \mathrm{~W}$, winding eddy current losses of $5.71 \mathrm{~W}$ and other stray losses of $2.81 \mathrm{~W}$. So that the dry transformer obtained an increase in losses of $11.643 \%$, including: increase in losses $3.66 \%$, increase in losses winding eddy current loss is $259.34 \%$ and the increase in other stray loss is $259.42 \%$ compared to a linear load.
2. The transformer with a linear load does not experience a decrease in its capacity. But when the transformer experiences a non-linear load with $\mathrm{THD}=39.1 \%$, the ability of the transformer to withstand the load is $84.294 \%$ from no load, and increasing the total harmonic distortion of the transformer current will increase the losses and reduce the rated capacity.

\section{References}

1. Grady, M. (2012). Understanding Power System Harmonics. Available at: https://web.ecs.baylor.edu/faculty/grady/understanding power_system_harmonics_grady_april_2012.pdf

2. Mehrdad, M., Stanek, E. K., Jannati, A. S. Influence of Voltage and Current Harmonics on Behavior of Electric Devices. Available at: http://citeseerx.ist.psu.edu/viewdoc/download?doi=10.1.1.519.4171\&rep=rep1\&type=pdf

3. Rexhepi, V. (2017). An Analysis of Power Transformer Outages and Reliability Monitoring. Energy Procedia, 141, 418-422. doi: https://doi.org/10.1016/j.egypro.2017.11.053

4. Godina, R., Rodrigues, E., Matias, J., Catalão, J. (2015). Effect of Loads and Other Key Factors on Oil-Transformer Ageing: Sustainability Benefits and Challenges. Energies, 8 (10), 12147-12186. doi: https://doi.org/10.3390/en81012147

5. Sadati, S. B., Tahani, A., Darvishi, B., Dargahi, M., Yousefi, H. (2008). Comparison of distribution transformer losses and capacity under linear and harmonic loads. 2008 IEEE 2nd International Power and Energy Conference. doi: https://doi.org/10.1109/ pecon.2008.4762661

6. Jayasinghe, R. N., Lucas, J. R., Perera, K. B. I. M. (2003). Power system harmonic effects on distribution transformers and new design considerations for $\mathrm{K}$ factor transformers. IEE Sri Lanka Annual Sessions.

7. EL Sebaay, A., Ramadan, M., Adma, M. A. A. (2017). Studying the Effect of Non-Linear Loads Harmonics on Electric Generator Power Rating Selection. European Scientific Journal, ESJ, 13 (18), 548. doi: https://doi.org/10.19044/esj.2017.v13n18p548

8. Kim, J.-G., Kim, J.-M. (2017). A study on the current \& load unbalance factor in using linear \& nonlinear load. The Transactions of The Korean Institute of Electrical Engineers, 66 (8), 1291-1296. doi: https://doi.org/10.5370/KIEE.2017.66.8.1291

9. Dalila, M. S., Khalid, M. N., Md Shah, M. (2009). Distribution transformer losses evaluation under non-linear load. 2009 Australasian Universities Power Engineering Conference.

10. Azbar, N. M., Jaffal, H. M., Freegah, B. (2020). Enhancement of the Thermal Performance Characteristics of an Electrical Power Transformer. Engineering Science \& Technology, 2 (1), 94-112. doi: https://doi.org/10.37256/est.132020487

11. Zynal, H. I., Yass, A. A. (2012). The Effect of Harmonic Distortion on a Three phase Transformer Losses. Canadian Journal on Electrical and Electronics Engineering, 3 (5), 255-261. Available at: https://citeseerx.ist.psu.edu/viewdoc/download?doi=10.1.1. $408.5299 \& \mathrm{rep}=\mathrm{rep} 1 \&$ type $=\mathrm{pdf}$

12. Singh, J., Singh, S., Singh, A. (2017). Effect of Harmonics on Distribution Transformer Losses and Capacity. International Journal of Engineering Technology Science and Research, 4 (6), 48-55. Available at: http://www.ijetsr.com/images/short_pdf/1497277266_ ieted683_ijetsr.pdf

13. Sajani, T. (2018). Design of the power feeding system for electrified railways case study: panadura- veyangoda railway sector University of Moratuwa. Available at: http://dl.lib.uom.lk/bitstream/handle/123/13427/Full-thesis.pdf?sequence=1

14. Papechen, P., Sebastian, S. (2016). A New RS Based Encryption Scheme for Wireless Communication. International Journal of Innovative Research in Electrical, Electronics, Instrumentation and Control Engineering, 4 (6), 268-272. Available at: https:// www.ijireeice.com/upload/2016/june-16/IJIREEICE\%2061.pdf

15. Olivares-Galván, J. C., Georgilakis, P. S., Ocon-Valdez, R. (2009). A Review of Transformer Losses. Electric Power Components and Systems, 37 (9), 1046-1062. doi: https://doi.org/10.1080/15325000902918990 